\title{
SOIL SETTLEMENT AND UPLIFT DAMAGE TO ARCHITECTURAL HERITAGE STRUCTURES IN BELGIUM: COUNTRY-SCALE RESULTS FROM AN INSAR-BASED ANALYSIS
}

\author{
ANASTASIOS DROUGKAS ${ }^{1 *}$, ELS VERSTRYNGE ${ }^{1 *}$, KOENRAAD VAN BALEN $^{1}$, \\ MICHAL SHIMONI ${ }^{2}$, THIBAULD CROONENBORGHS ${ }^{2}$, ROALD HAYEN $^{3}$, \\ PIERRE-YVES DECLERCQ ${ }^{4}$ AND JAN WALSTRA ${ }^{4}$ \\ ${ }^{1}$ Civil Engineering Department, KU Leuven \\ Kasteelpark Arenberg 40 Box 2448, B-3001 Heverlee, Belgium \\ Email: \{anastasios.drougkas,els.vestrynge,koenraad.vanbalen\}@kuleuven.be - Web page: \\ bwk.kuleuven.be/mat (*corresponding author) \\ ${ }^{2}$ Signal and Image Centre, Royal Military Academy \\ Avenue de la Renaissancelaan, 30,B-1000 Brussels, Belgium \\ Email: \{Michal.Shimoni,Thibauld.Croonenborghs\}@rma.ac.be - Web page: \\ http://www.sic.rma.ac.be/ \\ ${ }^{3}$ Royal Institute for Cultural Heritage \\ Parc du Cinquantenaire 1, B-1000 Brussels, Belgium \\ Email: roald.hayen@kikirpa.be - Web page: http://www.kikirpa.be \\ ${ }^{4}$ Geological Survey of Belgium, Royal Belgian Institute of Natural Sciences \\ Jennerstreet, 13, 1000 Brussels, Belgium \\ Email: \{pydeclercq, jwalstra\}@naturalsciences.be - Web page: \\ https://www.naturalsciences.be/en/science/do/25
}

Keywords: InSAR, Soil-Structure Interaction, Building Damage, Structural Monitoring, Data Analysis

\begin{abstract}
Soil movement may be induced by a wide variety of natural and anthropogenic causes, which are detectable in the local scale, but may influence the movement of the soil over vast geographical expanses. Space borne interferometric synthetic aperture radar (InSAR) measurements of ground movement provide a method for the remote sensing of soil settlement and uplift over wide geographic areas. Based on this settlement and uplift evaluation, the assessment of the potential damage to architectural heritage structures is possible. In this paper an interdisciplinary monitoring and analysis method is presented that processes satellite, cadastral, patrimonial and building geometry data, used for the calculation of settlement and uplift damage to architectural heritage structures in Belgium. It uses processed InSAR data for the determination of the soil movement profile around each case study, of which the typology is determined from patrimonial information databases and the geometry is calculated from digital elevation models. The impact on the historic structures is calculated from the determined soil movement profile based on various soilstructure interaction models for buildings. The
\end{abstract}


resulting damage is presented in terms of a numerical index illustrating its severity according to different criteria. In this way the potential soil movement damage is quantified in a large number of buildings in an easily interpretable and user-friendly fashion. The processing of InSAR data collected over the previous 3 decades allows the determination of the progress of settlement- and uplift-induced damage in this time period. With the integration of newly acquired and more accurate data, the methodology will continue to produce results in the coming years, both for the evaluation of soil settlement and uplift in Belgium as for introducing related damage risk data for existing architectural heritage buildings. Results of the analysis chain are presented in terms of potential current damage for selected areas and buildings.

\section{INTRODUCTION}

The investigation of the response of building structures to soil subsidence and uplift is of great importance [1]. Historic buildings, which are often inherently lacking in ductility and left without effective maintenance, are especially vulnerable to damage induced by soil movement. It is therefore critical to develop analysis techniques specifically for existing and historic structures.

In the study of individual structures, it is possible to adopt finite element modelling for the analysis of the structure, since computational cost is not a critical issue [2]. Analysis of larger numbers of buildings over a wider area require the adoption of different strategies for the determination of the loading and the analysis of the buildings [3]. When denling with country-scale assessment, a level which can affect decision-making and strategy at higher administrative echelons, presentation. Space-borne Synthetic Aperture Interferometry powerful tool for the de methods can be used for the amalysis of any sidence clusters of buildings to entire cities. Application in soil-structure interaction thus far has

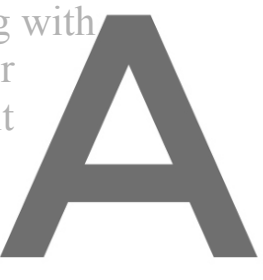

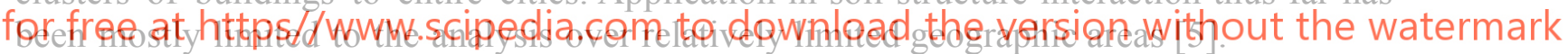

Major difficulties arise in attempting to determine soil movement profiles for

individual buildings using InSAR over wide geographic areas. Data point density may be too low for the accurate determination of the soil movement in the area of a particular building. Therefore, the calculation of soil movement intensity parameters commonly used in analytical models [6] may be problematic.

This paper presents a method for the country-scale analysis of buildings subjected to soil subsidence- and uplift-induced damage over an extended time-period. The method consists in country-scale processing of InSAR data, the processing of patrimonial and cadastral data, the calculation of soil movement intensity parameters from limited data and the calculation of damage potentially induced over the investigated period. The method is applied in the entirety of Belgium, involving thousands of architectural heritage buildings.

\section{SATELLITE DATA ACQUISITION}

\subsection{Data Acquisition}

Ground displacement, such as subsidence, uplift and horizontal movement can be calculated using InSAR. These methods rely on the measurement of distance change between emission 
antennas and points on the ground between successive satellite passages. This distance is calculated through the phase difference of the signal emitted by the antenna, reflected on the point on the ground and finally received by the antenna.

The reflection points on the ground are called Persistent Scatterers (PS) and are characterized by high amplitude of reflection and good temporal [7] and spatial [8] correlation. These points are often located on buildings or other human-made constructions (e.g. at the roofs of buildings) and provide info on the vertical velocity at which a point is subsiding or uplifting.

\subsection{Data Processing}

PS data is processed using the StaMPS processing chain [9]. PS data collected over 26 years is used in this study, covering the period 1992-2018. This data was collected by three satellites covering the entirety of Belgium at different time periods: ERS 1/2, EnviSAT and Sentinel 1. The number of PS identified for each time period varies, but an average of $800 \mathrm{PS} / \mathrm{Km}^{2}$ was attained in urban areas where the largest number of potential reflectors is located. For the construction of ground movement velocity fields over the area of Belgium, the PS velocity data is interpolated through inverse distance weighing with a grid spacing of $10 \mathrm{~m}$.

\section{BUILDING DATA}

\subsection{Identification of Analysis Cases}

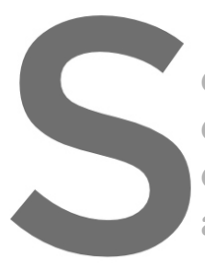

The buildings to databases of the thre databases contain basic object. Several database are not affected by soil analysed are identified
ederal regions of Belgitom
information on the age
entries refer to objects ed through data
gium: Brussels,
ge, typology and
s which cannot b
es include natura
is possible to is a mined from the
Flanders and Wallo
be considered build
ral oujects parks and patrimonial
lonia. These
y registored
dings of that
d sculptures
should be or public art. Through analysis of this data it is possible to isolate entries which should be considered for analysis.

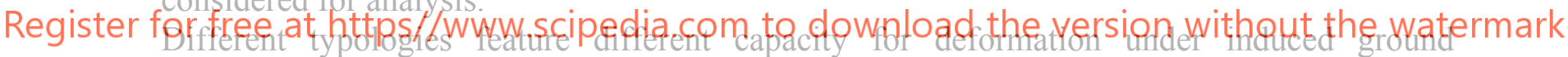
movement. Bare frames are more ductile than infilled frames, which are in turn more ductile than masonry buildings. Data extracted from the databases allows the allocation of each building to one of these three types.

Overall, 269194 analysis cases were identified for Belgium, corresponding to roughly $70 \%$ of all patrimonial database entries.

\subsection{Building Polygons}

Through cross-processing of the patrimonial and cadastral databases of Belgium, the plan of each building was determined, represented by a polygon on the surface of the ground. The height of every building was calculated from subtraction of the digital terrain model from the digital surface model of the country.

In the study of soil-structure interaction, the movement of soil within a certain distance of a building can induce deformation on the superstructure. In order to consider this effect, an area of influence for each polygon was calculated, consisting in an outward offset of $10 \mathrm{~m}$. The PS and interpolated grid values which fall within the area of interest are considered for the calculation of potential damage in each analysis case. Due to the grid spacing of $10 \mathrm{~m}$, every 
analysis case is guaranteed to include several grid velocity data points. This is critical for damage calculation due to soil subsidence and uplift, which is a function of the ground deformation gradient in an area rather than simply its magnitude.

\section{SOIL DEFORMATION PROFILE}

\subsection{Calculation of Soil Deformation Surface}

Country-scale processing of InSAR data results in a low density of PS due to processing power limitations. Therefore, it is not generally possible to extract detailed soil deformation profiles from the InSAR data available. In order to overcome this problem, an approach capable of calculating a simplified soil deformation profile from limited data is presented here.

A minimum of three data points in $R^{3}$ space is required for the calculation of a threedimensional linear surface $f$. By assuming that the dip direction of the surface coincides with the direction of the vector connecting two points, then only these two points are required for the calculation of the surface. In the present context, each point is defined by two geographic coordinates and a value of vertical displacement. These points are provided by the PS or interpolated grid data. Based on these parameters, a surface of the type:

$$
f(x, y)=a+b x+c y
$$

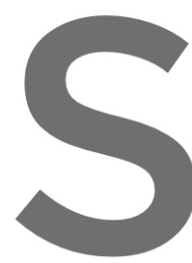

\section{where $(x, y)$ are geographical from two points. This sir coordinate pair. When the pair of points that $y$ distance $s$ to horizontal distance $d$ :}
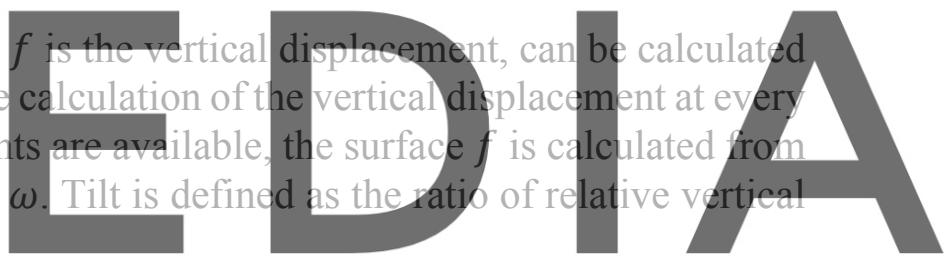

Register for free at https//www.scipedia.com to $\underset{\omega}{\mathrm{d}} \frac{\mathrm{q}}{\mathrm{d}} \mathrm{wnload}$ the version without the watermark

This calculation is executed for each of the building polygons of the analysis cases. The combination of the $10 \mathrm{~m}$ interpolation grid with the assumption of the dip direction of $f$ ensures that $f$ can be calculated for every analysis case regardless of PS density in the area of the polygon.

Considering the maximum tilt for the analysis is a conservative assumption. However, this assumption is supported by two facts: a) the number of PS per building polygon is low, even in urban areas where there is an abundance of reflectors, b) the maximum tilt approach can assist in highlighting local effects near the individual buildings which might otherwise be smeared out in a country-scale evaluation of InSAR data.

\subsection{Calculation of Building Polygon Loading}

By substituting the coordinates of the vertices of each building polygon to function $f$ it is possible to determine the vertical movement each vertex. Since PS data provides info on the vertical velocity, the vertical displacement is calculated by multiplication of the velocity with 
the length of time of the investigated period.

By substituting the relative vertical displacement values $s$ for the vertices of each polygon edge to eq. (2) and dividing by the length $d$ of the edge, the tilt $\omega$ for every edge is calculated. It is thus possible to calculate the damage at different parts of the structure according to the direction of tilting in the area near each building.

\section{DAMAGE MODELLING}

Each structure considered for analysis was placed in one of three categories depending on structural typology: a) masonry, b) infilled frame and c) bare frame structures. These typologies generally present very different sensitivity to soil movement, with masonry being the most sensitive and bare frames being the least sensitive to subsidence and uplift.

For the calculation of potential damage of the buildings, an approach of limits on the tilt is adopted. In this approach, the tilt of all the edges in every polygon is calculated according to eq. (2). The maximum tilt among the edges of the polygon is translated to a damage index $I$ in the range of $[0,3]$. Based on this damage index, four damage levels are considered: a) null to negligible for $I \in[0,1)$, b) slight to light for $I \in[1,2)$, c) moderate to severe for $I \in[2,3)$ and d) very severe for $I=3$. These damage levels correspond to indicative crack widths [10] as presented in Table 1.

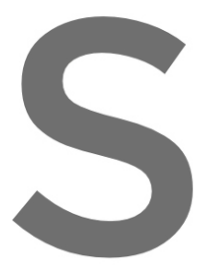

Table 1: Correspondance between damage index, damage level and crack width in masonry strutures.
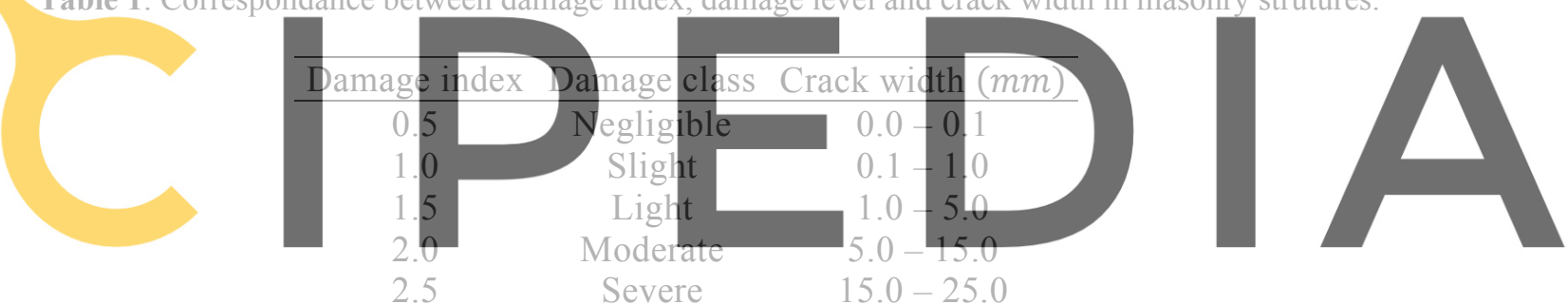

Register for free at https//www.seipedia.cळmytoldownload-the version without the watermark

Based on the tilt limits proposed by Fischer [11], the damage index I in masonry or infilled frames as a function of the tilt $\omega$ is:

$$
I(\omega)=\left\{\begin{array}{ccc}
0.75\left(0+\frac{\omega-0.000}{0.001-0.000}\right) & \text { if } & 0.000 \leq \omega \leq 0.001 \\
0.75\left(1+\frac{\omega-0.001}{0.002-0.001}\right) & \text { if } & 0.001 \leq \omega \leq 0.002 \\
0.75\left(2+\frac{\omega-0.002}{0.003-0.002}\right) & \text { if } & 0.002 \leq \omega \leq 0.003 \\
0.75\left(3+\frac{\omega-0.003}{0.005-0.003}\right) & \text { if } & 0.003 \leq \omega \leq 0.005 \\
3 & \text { if } & 0.005 \leq \omega
\end{array}\right.
$$

Considering the relatively higher ductility of bare frames compared to masonry or infilled frames [12], the damage index $I$ for bare frames reads: 


$$
I(\omega)=\left\{\begin{array}{ccc}
0.75\left(0+\frac{\omega-0.000}{0.002-0.000}\right) & \text { if } & 0.000 \leq \omega \leq 0.002 \\
0.75\left(1+\frac{\omega-0.002}{0.004-0.002}\right) & \text { if } & 0.002 \leq \omega \leq 0.004 \\
0.75\left(2+\frac{\omega-0.004}{0.006-0.004}\right) & \text { if } & 0.004 \leq \omega \leq 0.006 \\
0.75\left(3+\frac{\omega-0.006}{0.010-0.006}\right) & \text { if } & 0.006 \leq \omega \leq 0.010 \\
3 & \text { if } & 0.010 \leq \omega
\end{array}\right.
$$

It is assumed, as shown in eq. (3), that infilled frames present the same sensitivity to subsidence and uplift as masonry structures. This assumption is supported by the fact that masonry infills are the most sensitive part of infilled frames and the location where the majority of damage in infilled frame buildings subjected to soil-movement develons. The curves of eq. (3) and (4) are plotted in Figure 1 .
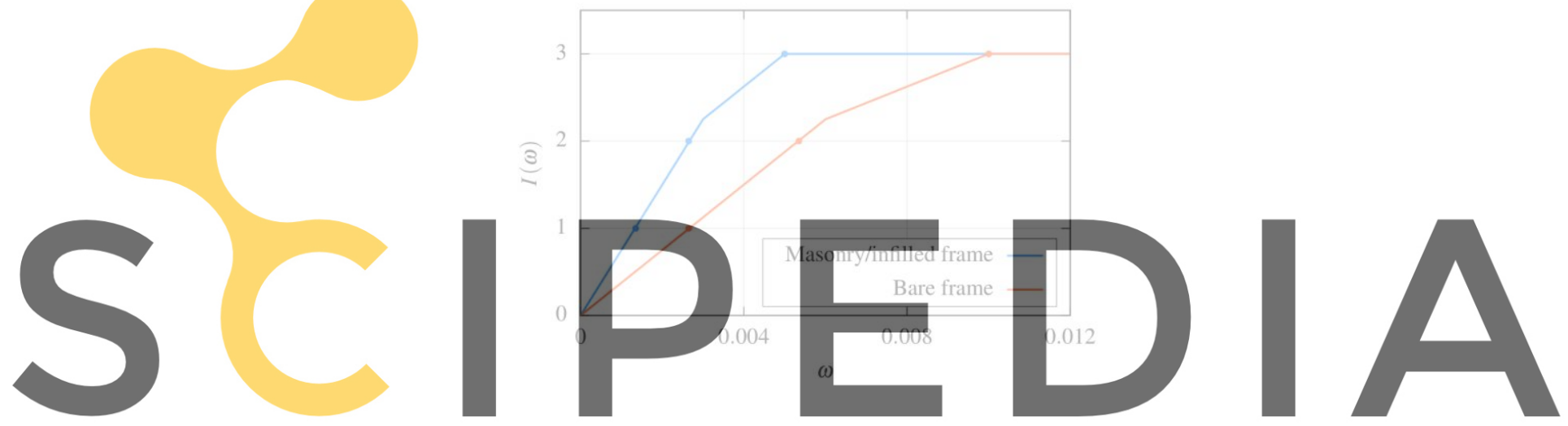

\section{Register for free at https//www.scipedia.com to download the version without the watermark}

The damage calculation is performed by accumulating the tilt that occurs during the different measurement periods. The model cannot consider damage that occurred before the beginning of the measurement in 1992. However, when manually working on individual cases, an initial damage index can be introduced, the calculation further increasing the damage index from accumulated tilt due to soil subsidence and uplift.

For the validation of the damage model, the building cases summarized by Namazi and Mohamad are used [13]. The building typology has been reported, along with a qualitative description of the damage reported. Only the cases where the tilt was directly reported were considered in this validation, amounting to 10 cases. The considered cases and the analysis results are presented in Table 2. The comparison of the reported with the predicted damage reveals that the employed damage model results in a generally accurate qualitative prediction of the damage. A small underestimation of the predicted damage is obtained in 2 cases with reported severe damage and a small overestimation is obtained in one case with moderate reported damage. 
Table 2: Validation of damage model based on case studies from literature: comparison of reported with predicted damage levels. Accurate damage prediction highlighted in green, overestimation in blue and underestimation in red.

\begin{tabular}{ccccccc}
\hline No. & Ref. & Building type & Reported damage & $\omega$ & $I(\omega)$ & Predicted damage \\
\hline 1 & {$[15]$} & RC & Severe & $1 / 361$ & 2.078 & Moderate \\
2 & {$[16]$} & RC & Negligible & $1 / 900$ & 0.833 & Slight \\
3 & {$[16]$} & Masonry & Very severe & $1 / 240$ & 2.688 & Severe \\
4 & {$[17]$} & Masonry & Very slight & $1 / 520$ & 1.442 & Slight \\
5 & {$[17]$} & Masonry & Slight & $1 / 3330$ & 0.225 & Negligible \\
6 & {$[18]$} & RC & Negligible & $1 / 8333$ & 0.090 & Negligible \\
7 & {$[19]$} & Masonry & Slight & $1 / 388$ & 1.933 & Light \\
8 & {$[22]$} & Masonry & Moderate & $1 / 225$ & 2.792 & Severe \\
9 & {$[23]$} & Masonry & Very severe & $1 / 278$ & 2.474 & Moderate \\
10 & {$[24]$} & RC & Slight & $1 / 435$ & 1.724 & Light
\end{tabular}

\section{ANALYSIS RESULTS}

\subsection{Potential Damage Calculation}

The results of the analysis for the entirety of Belgium are plotted in Figure 2. The figure shows the number of buildings for each damage level at the end of the measurement period.

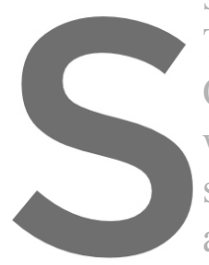

The results are presente

Overall, thousands of buil

which corresponds to

structures, distributed cr

a damage index $I$ of 1.0 , indicating slight dam
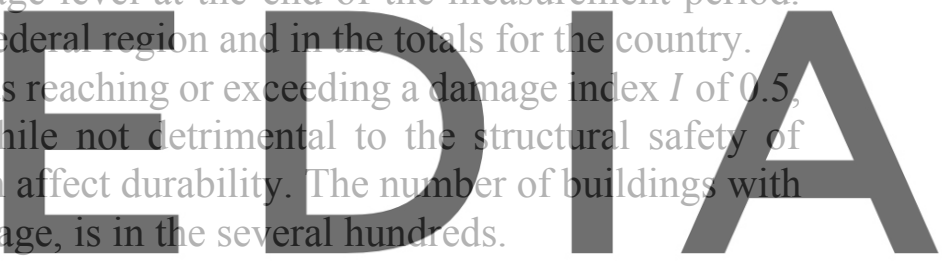

There is a foreseen drop in the number of buildings with potential light and moderate damage

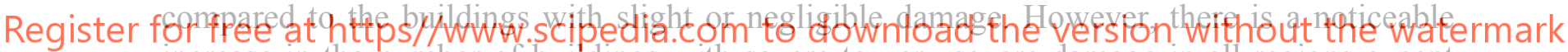
increase in the number of buildings with severe to very severe damage in all regions except

Flanders, compared to the number of lightly to moderately damaged buildings. This is a possible effect of the conservative adoption of the maximum tilt curve $f$. This effect is more pronounced in Brussels, which is characterised by high-density InSAR data.

The majority of buildings with potential damage are located in Flanders, which also features the most populated patrimonial database. The number of potentially damaged buildings in Wallonia is low, yet in percentage compared to the total number of listed buildings, results are comparable among the three regions. 


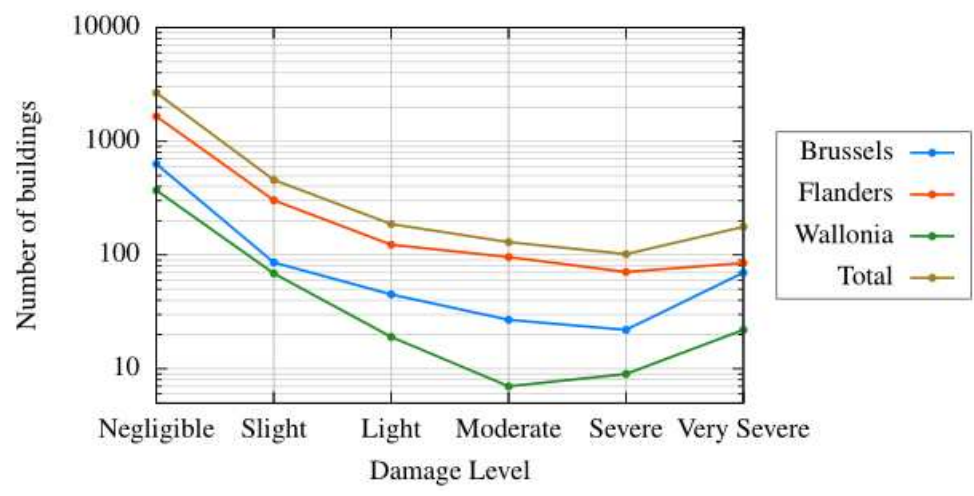

Figure 2: Potential damage analysis results for Belgium.

\subsection{Verification and Evaluation of Analysis Results}

The verification of the analysis results is accomplished through a sample inspection of selected buildings. Sixteen buildings were identified in the region of Limburg (Flanders) for inspection. The results of the analysis are summarised in Table 3.

Table 3: Potential damage prediction results for selected case studies.
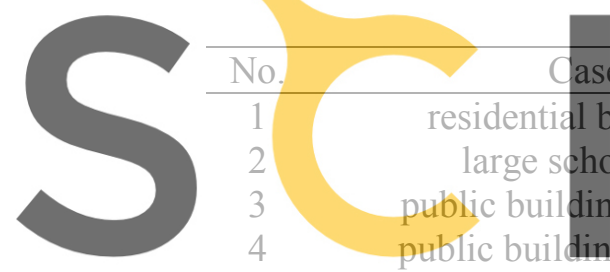

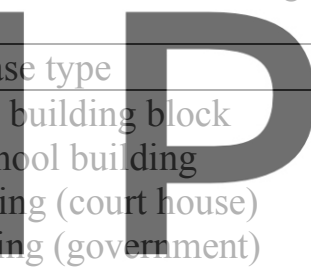

town house

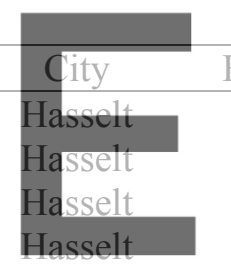

Hasselt

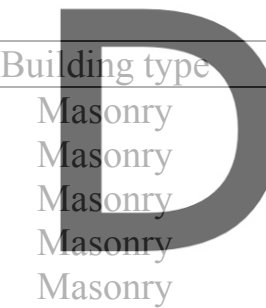

0.07

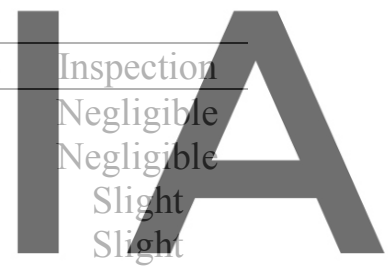

Slight

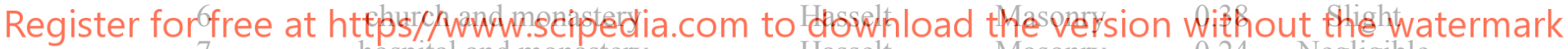

8 industrial heritage (mining

concession)

$9 \quad$ public building (swimming pool)

10 church

11 industrial heritage (mining concession)

12 industrial heritage (mining concession)

13

14

15

16 church with cemetery town house workers' housing coupled town houses
Hasselt

Genk

Masonry

Masonry + RC

0.24 Negligible

0.15 Moderate

\begin{tabular}{|c|c|c|c|}
\hline Genk & $\mathrm{RC}$ & 0.08 & Negligible \\
\hline Meeuwen & Masonry & 0.21 & Light \\
\hline Koersel & $\mathrm{RC}$ & 0.17 & Negligible \\
\hline Koersel & $\mathrm{RC}$ & 0.17 & Negligible \\
\hline Donk & Masonry & 0.05 & Negligible \\
\hline Leuven & Masonry & 3.00 & Severe* \\
\hline Leuven & Masonry & 3.00 & Severe \\
\hline Leuven & Masonry & 2.48 & Moderate \\
\hline
\end{tabular}

${ }^{*}$ Undergone structural renovation during measurement period

Despite having higher registered tilt values than other buildings in the immediate vicinity, the calculated potential damage was mostly negligible. Site inspection revealed no apparent damage for half of these structures. The other half presented slight to moderate damage, which, 
according to the inspection, was sustained and repaired before the measurement period. Therefore, the analysis results are considered to be in agreement with or more conservative than the site findings. Further, three buildings were singled-out for inspection in the city of Leuven. According to the analysis results, the potential damage in one of the buildings is moderate, while in the remaining two the potential damage is severe. One of the structures with predicted severe damage presented substantial ground movement-induced damage. The other building with predicted severe damage and the building with predicted moderate damage have undergone extensive structural renovation during the measurement period. Whether the interventions were due to ground movement damage, or whether the interventions themselves are responsible for the acquired measurements, is unclear. Regardless, the acquired data was able to reflect the movement on the building.

Due to the wide scope of the analysis, the total number of buildings affected by soil movement, namely buildings with any level of potential damage, is very high. It is noted, however, that some of these damages may have already been detected and repaired in the past. Nevertheless, potential damage that has arisen in more recent periods, as well as registered high intensity soil deformation, can assist in directing and focusing site inspection and structural movement monitoring efforts.

\section{CONCLUSIONS}

This paper presents a method for the acquisition and processing of InSAR and patrimonial data for their use in th subsidence and uplift. to be practical for coun applicable in cases of arbitrary A large number of pote agreement with the anary sis restits.
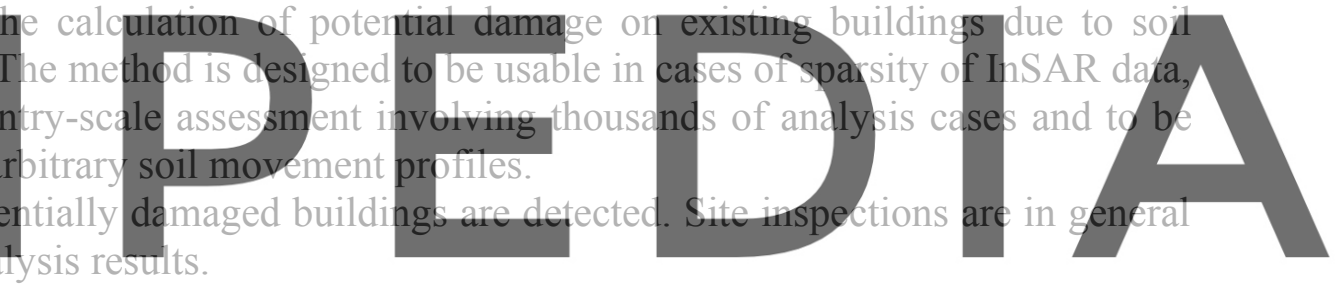

Due to its flexibility, the proposed method is in principle equally applicable to smaller-scale

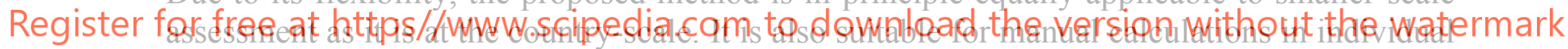
buildings, where pre-existing damage can be included in the analysis.

Acknowledgements. The authors wish to acknowledge the funding received by BRAIN.be, BelSPO in support of the GEPATAR research project ("GEotechnical and Patrimonial Archives Toolbox for ARchitectural conservation in Belgium” BR/132/A6/Gepatar).

\section{REFERENCES}

[1] A. Amorosi, D. Boldini, G. de Felice, M. Malena, M. Sebastianelli, Tunnelling-induced deformation and damage on historical masonry structures, Géotechnique. 64 (2014) 118-130. doi:10.1680/geot.13.P.032.

[2] A. Drougkas, E. Verstrynge, P. Szekér, G. Heirman, L.-E. Bejarano-Urrego, G. Giardina, K. Van Balen, Numerical Modeling of a Church Nave Wall Subjected to Differential Settlements: Soil-Structure Interaction, Time-Dependence and Sensitivity Analysis, Int. J. Archit. Herit. (2020). doi:10.1080/15583058.2019.1602682.

[3] D. Peduto, G. Nicodemo, J. Maccabiani, S. Ferlisi, Multi-scale analysis of settlementinduced building damage using damage surveys and DInSAR data: A case study in The 
Netherlands, Eng. Geol. 218 (2017) 117-133. doi:10.1016/j.enggeo.2016.12.018.

[4] J. Walstra, C. Barbier, L.-E. Bejarano-Urrego, P.-Y. Declercq, D. Derauw, A. Drougkas, R. Hayen, F.-P. Hocquet, J.-F. Lopez, M. Shimoni, K. Van Balen, E. Verstrynge, The GEPATAR project: GEotechnical and Patrimonial Archives Toolbox for ARchitectural conservation in Belgium, in: Eur. Geosci. Union Gen. Assem. Vienna, 2018: p. 15918.

[5] P. Milillo, G. Giardina, M.J. DeJong, D. Perissin, G. Milillo, Multi-temporal InSAR structural damage assessment: The London crossrail case study, Remote Sens. 10 (2018) 20-22. doi:10.3390/rs10020287.

[6] D. Peduto, M. Korff, G. Nicodemo, A. Marchese, S. Ferlisi, Empirical fragility curves for settlement-affected buildings: Analysis of different intensity parameters for seven hundred masonry buildings in The Netherlands, Soils Found. 59 (2019) 380-397. doi:10.1016/j.sandf.2018.12.009.

[7] A. Ferretti, C. Prati, F. Rocca, Permanent scatterers in SAR interferometry, IEEE Trans. Geosci. Remote Sens. 39 (2001) 8-20. doi:10.1109/36.898661.

[8] A. Hooper, H. Zebker, P. Segall, B. Kampes, A new method for measuring deformation on volcanoes and other natural terrains using InSAR persistent scatterers, Geophys. Res. Lett. 31 (2004) 1-5. doi:10.1029/2004GL021737.

[9] A. Hooper, D. Bekaert, K. Spaans, M. Arikan, Recent advances in SAR interferometry time series analysis for measuring crustal deformation, Tectonophysics. 514 (2012) 1-

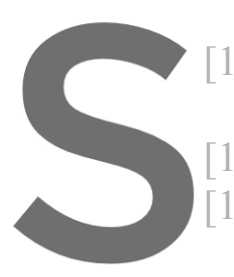
13. doi:10.1016/j.tecto.2011.10.013.

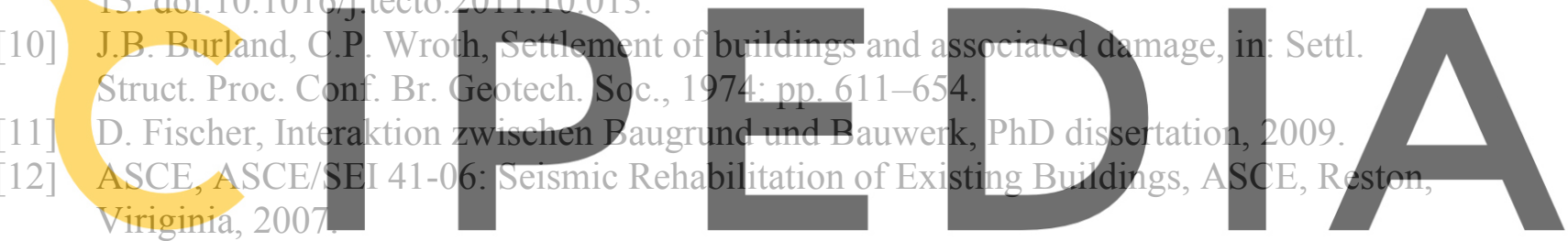

[13] E. Namazi, H. Mohamad, Potential damage assessment in buildings undergoing tilt,

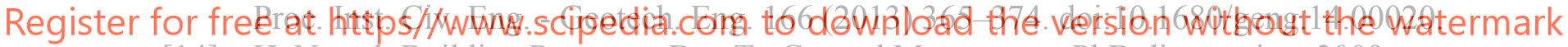

[14] H. Netzel, Building Response Due To Ground Movements, PhD dissertation, 2009.

[15] A.W. Skempton, D.H. MacDonald, The allowable settlement of buildings, Proc. Inst. Civ. Eng. 5 (1956) 727-768.

[16] H. Breth, G. Chambosse, Settlement behavior of buildings above subway tunnels in Frankfurt clay, in: Proc. Conf. Os Settl. Struct., 1974: pp. 329-333.

[17] M.D. Boscardin, E.J. Cording, Building Response to Excavation-Induced Settlement, J. Geotech. Eng. 115 (1989) 1-21.

[18] J.R. Standing, Elizabeth House, Waterloo, in: J.B. Burland, J.R. Standing, F.M. Jardine (Eds.), Case Stud. from Constr. Jubil. Line Extension, London, Thomas Telford, London, 2001: pp. 547-612.

[19] J. Anketell-Jones, J.B. Burland, The Mansion House Revisited, in: Proc. Int. Conf. Response Build. to Excav. Gr. Movements, 2003: pp. 165-176.

[20] R.J. Finno, F.T. Voss, E. Rossow, J.T. Blackburn, Evaluating Damage Potential in Buildings Affected by Excavations, J. Geotech. Geoenvironmental Eng. 131 (2005) 1199-1210. doi:10.1061/(ASCE)1090-0241(2005)131:10(1199).

[21] I.A. Macleod, J.G. Paul, Settlement monitoring of buildings in Central Scotland, Geotechnique. 34 (1984) 99-117. 
[22] J. Li, D.A. Cameron, Case Study of Courtyard House Damaged by Expansive Soils, J. Perform. Constr. Facil. 16 (2002) 169-175.

[23] J. Li, Case Study of Movement and Damage to a Residential Building Founded on Expansive Clays, in: Geotech. Eng. Disaster Mitig. Rehabil., 2008: pp. 689-694.

[24] C. Ou, J. Liao, W. Cheng, Building response and ground movements induced by a deep excavation, Géotechnique. 50 (2000) 209-220. 